\title{
Article
}

\section{Micro Vascular Changes in the Placenta of Bangladeshi Overt Diabetic Mothers and Hypertensive Diabetic Mothers}

\author{
Rahman $\mathbf{H}^{1}$, Khalil $\mathbf{M}^{2}$, Ferdousi $\mathbf{R}^{3}$, Uddin $\mathbf{M}^{4}$, Chowdhury $\mathbf{M M}^{5}$, Sultana $\mathrm{SZ}^{6}$, Mannan $\mathrm{S}^{7}$
}

It is a significant medical problem when Pregnancy is complicated by diabetes and/or hypertension which affect not only affecting maternal health, but also jeopardizing fetal normalcy? The placenta being the bridge between maternal fetal activities, this structure is considered as a window through which understanding of maternal dysfunctions as well as of their impacts on fetal wellbeing can be obtained. And as it is an almost all-vessel organ, its functional status depends primarily on the structural status of its vessels. To observe vascular changes in the placenta, a study was carried out on 44 placentas. 19 from overt diabetic mothers having no hypertension and 5 from hypertensive diabetic mothers, and 20 from control group having no hypertension or diabetes. These were collected just after delivery though caesarian section. Microscopic findings of the study were that there was a trend of greater intimal thickness at the second branching site in the overt diabetes group than the control group. But at the first and last branching site this tendency was reversed. But none of these tendencies reached statistical significance. In case of the hypertensive diabetes group, there was a tendency of greater intimal thickness at the first, second and last branching sites as compared to the control group. Hypertensive diabetes group also showed significantly greater intimal thickness at first and last branching sites than the overt diabetes group.

Key wards: Placenta, diabetes, blood vessels, hypertension

J Bangladesh Soc Physiol. 2006 Dec;(1):27-34. For author affiliations, see end of text.

\section{Introduction}

$\mathbf{H}$ uman placenta is a highly vascular organ. The volume and flow of blood through placenta is kept adequate by its characteristic vascular arrangement. As placenta performs essential abortive, endocrine, metabolic, exchange and excretory functions during pregnancy, many vascular changes are very likely to affect placental functions and there by, fetal wellbeing. Pregnancy complicated with diabetes is a well known risk factor for increasing perinatal mortality and morbidity. $4,15,18,24,25$ It is observed that infants of both overt and gestational diabetic mothers suffer more from antenatal and neonatal problems than the infants of non diabetic mothers. ${ }^{1,4,24}$ Increase size of placenta was observed in J Bangladesh Soc Physiol. 2006 Dec;(1):27-34 diabetic mothers. 22, 37 Congenital malformations are more common in the infant of diabetic mothers than those of non diabetic mothers. ${ }^{4,23}$

\section{Methods}

The study was carried out in the department of Anatomy, Banga Bandhu Sheikh Mujib Medical University (BSMMU), Dhaka during the period of January 2002 to July 2003. The placenta was collected from a total 44 mothers after caesarian section from BIRDEM Hospital in the period of April 2002 to November 2002. Selection criteria of the woman were (a) delivered by caesarian section and (b) different laboratory 


\section{Article}

tests were done in BIRDEM Hospital. mother who had pre ecliptic toxemia (PET) or eclampsia, Rh incompatibility, antepartem hemorrhage, a positive test for HBsAg, a positive test for VDRL, present multiple pregnancy were excluded from the study, Out of 44, 20 from mothers of non diabetic and non hypertensive, 19 from diabetic but non hypertensive and 5 from diabetic hypertensive mothers. Just after delivery placenta was collected and trimming was done and variables of placenta were examined.

\section{Results}

Microscopic findings of the study were that there was a trend of greater intimal thickness at the second branching site in the overt diabetes group than the control group (Table - I and Figure 1). But at the first and last branching site this tendency was reversed. But none of these tendencies reached statistical significance. In case of the hypertensive diabetes group, there was a tendency of greater intimal thickness at the first, second and last branching sites as compared to the control group. Hypertensive diabetes group also showed significantly greater intimal thickness at first and last branching sites than the overt diabetes group.

Table I: Intimal thickness of a chorionic artery at three branching sites in different groups

\begin{tabular}{|c|c|c|c|c|}
\hline Variable & Control (C) & $\begin{array}{c}\text { Overt diabetes } \\
(\mathrm{OD})\end{array}$ & $\begin{array}{l}\text { Hypertensive } \\
\text { diabetes (HD) }\end{array}$ & $\begin{array}{c}\text { Significance of } \\
\text { difference* }\end{array}$ \\
\hline \multicolumn{5}{|l|}{ At the $1^{\text {st }}$ branching site: } \\
\hline Number of vessels (n) & 13 & 16 & 4 & \\
\hline \multicolumn{5}{|l|}{ Intimal thickness $(\mu \mathrm{m})$} \\
\hline Range & $18-162$ & $13-127$ & $58-255$ & OD vs. C: NS \\
\hline \multirow[t]{2}{*}{ Mean \pm SD } & $84.15 \pm 42.25$ & $65.94 \pm 37.14$ & $124.75 \pm 88.76$ & HD vs. C:NS \\
\hline & & & HD vs. OD: S & \\
\hline \multicolumn{5}{|l|}{ At the $2^{\text {nd }}$ branching site: } \\
\hline Number of vessels (n) & 12 & 14 & 4 & \\
\hline \multicolumn{5}{|l|}{ Intimal thickness $(\mu \mathrm{m})$} \\
\hline Range & $23-165$ & $7-148$ & $80-158$ & OD vs. C: NS \\
\hline \multirow[t]{2}{*}{ Mean \pm SD } & $77.25 \pm 42.98$ & $84.79 \pm 43.93$ & $100.75 \pm 47.45$ & HD vs. C: NS \\
\hline & & & HD vs. OD: NS & \\
\hline \multicolumn{5}{|l|}{ At the last branching site: } \\
\hline Number of vessels (n) & 12 & 13 & 5 & \\
\hline \multicolumn{5}{|l|}{ Intimal thickness $(\mu \mathrm{m})$} \\
\hline Range & $7-155$ & $7-75$ & $38-210$ & OD vs. C: NS \\
\hline \multirow[t]{2}{*}{ Mean \pm SD } & $56.17 \pm 54.84$ & $29.77 \pm 23.70$ & $99.20 \pm 75.89$ & HD vs. C: NS \\
\hline & & & & HD vs. OD: $\mathrm{S}$ \\
\hline
\end{tabular}

*To compare each group with every other group (i.e. OD vs. C, HD vs. C, HD vs. OD) for every variable the Post Hoc option of analysis of variance (ANOVA) was used and the difference was considered as significant if Pd"0.05 was detected, S: Significant, NS: Not significant. 


\section{Article}

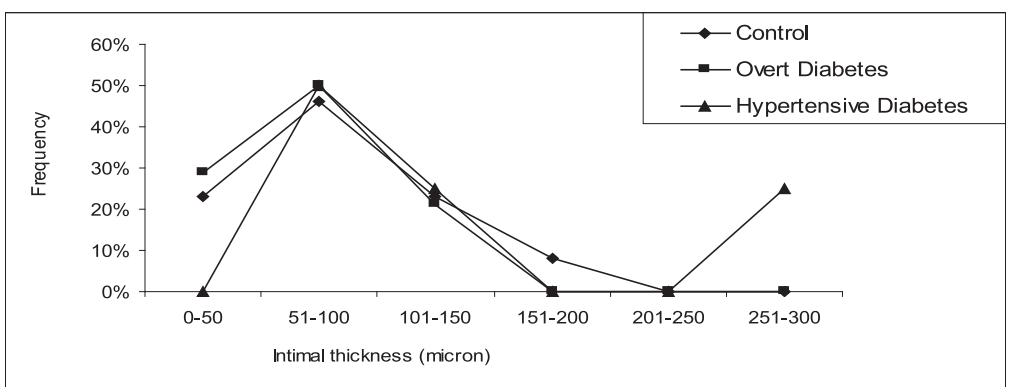

First branching site

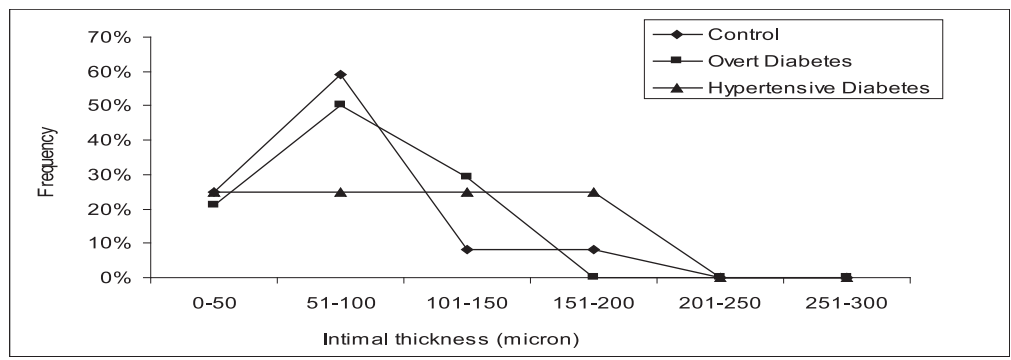

Second branching site

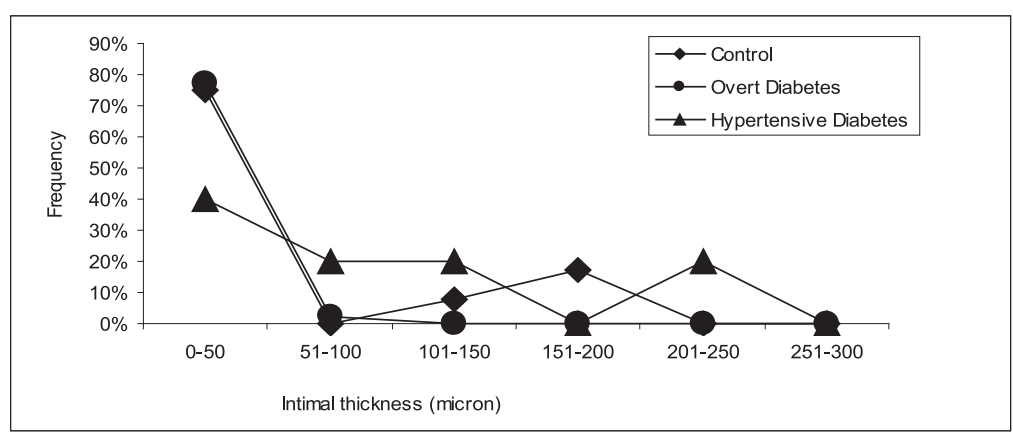

Last branching site

Figure 1. Clearly depicts frequency curves for intimal thickness at three different sites in different groups.

Cross-sectional area of the lumen of a chorionic artery is reduced due development of atherosclerotic lesions in the arterial wall.

The comparative findings of the luminal cross sectional area in the three different groups at the three different sites for each are presented in Table II. A tendency of the cross sectional luminal area being smaller was observed in the Overt Diabetic group at the last branching site compared to the Control group, but it was reversed at the first and second branching sites being significantly so at the second branching site.

J Bangladesh Soc Physiol. 2006 Dec;(1):27-34
In the hypertensive diabetes group there was a tendency towards smaller cross-sectional luminal area was observed at the first and second branching sites compared to the control group. At the second branching site, it was significantly lower than in the control group. But at the last branching site there was a tendency towards a larger crosssectional area not attaining significance.

Compared to the overt diabetic group these differences were significant for the first and second branching sites. For the last branching site, hypertensive diabetic group had a higher mean value, though statistically not significant. 


\section{Article}

Table - II. Cross-sectional area of the residual lumen of a chorionic artery at three branching sites in different groups

\begin{tabular}{|c|c|c|c|c|}
\hline Variable & Control (C) & $\begin{array}{c}\text { Overt Diabetes) } \\
\text { (OD } \\
\end{array}$ & $\begin{array}{c}\text { Hypertensive } \\
\text { Diabetes (HD) }\end{array}$ & $\begin{array}{c}\text { Significance } \\
\text { of difference* }\end{array}$ \\
\hline \multicolumn{5}{|l|}{ At the $1^{\text {st }}$ branching site: } \\
\hline Number of sections (n) & 18 & 16 & 4 & \\
\hline \multicolumn{5}{|l|}{$\begin{array}{l}\text { Cross sectional area } \\
(\text { sq. }(\mu \mathrm{m})\end{array}$} \\
\hline Range & 420-11406 & 613-21051 & $708-2173$ & OD vs. C: NS \\
\hline Mean \pm SD & $2706.67 \pm 2825.04$ & $5937.13 \pm 6131.72$ & $1484.75 \pm 604.99$ & $\begin{array}{l}\text { HD vs. C: NS } \\
\text { HD vs. OD: } S\end{array}$ \\
\hline \multicolumn{5}{|l|}{ At the $2^{\text {nd }}$ branching site: } \\
\hline \multicolumn{5}{|l|}{$\begin{array}{l}\text { Cross sectional area } \\
(\mathrm{sq} . \mu \mathrm{m})\end{array}$} \\
\hline Range & $130-7741$ & $86-9995$ & 240-1068 & OD vs. C: S \\
\hline Mean \pm SD & $1401.53 \pm 2161.76$ & $1830.94 \pm 2675.39$ & $\begin{array}{c}593.75 \pm 360.84 \\
\text { HD vs. OD: } S\end{array}$ & HD vs. C: $\mathrm{S}$ \\
\hline \multicolumn{5}{|l|}{ At the last branching site: } \\
\hline Number of cases (n) & 16 & 16 & 5 & \\
\hline \multicolumn{5}{|c|}{ Cross sectional area (sq. $\mu \mathrm{m})$} \\
\hline Range & $4-2841$ & $12-1530$ & 76-1870 & OD vs. C: NS \\
\hline Mean \pm SD & $387.31 \pm 712.94$ & $248.07 \pm 402.13$ & $742.40 \pm 749.47$ & $\begin{array}{l}\text { HD vs. C: NS } \\
\text { HD vs. OD: NS }\end{array}$ \\
\hline
\end{tabular}

*To compare each group with every other group (i.e. OD vs. C, HD vs. C, HD vs. OD) for every variable the Post Hoc option of analysis of variance (ANOVA) was used and the difference was considered as significant if Pd" 0.05 was detected, S: Significant, NS: Not significant

\section{Discussion}

The placenta is the only organ developed from two different individuals ${ }^{17}$, the gross anatomy of which is its vascular anatomy ${ }^{8}$. It acts as a fetal lung where exchange takes place between maternal (uteroplacental) circulation and fetal (feto-placental) circulation. The two circulations, maternal and fetal, are so closely related to each other that any condition of one whether physiological or pathological should reflect on the others. Any condition which reduces the blood flow in the placental bed hampers the development of the placenta and, therefore, of the fetus. Ischemia could be responsible for many of the observed placental changes. ${ }^{16,28,30}$ It is very difficult to assess which of the two circulations is affected more in particular types of pathology. There are different opinions regarding the relative percentage of contribution of these two. Though uteroplacental and fetoplacental blood flow are major determinants of maternal placental exchanges, Desoye and Shafrir ${ }^{9}$ indicated that uetroplacental circulation is more important for placental supply while fetoplacental circulation is more important for fetal nutrient supply. Giles et al (1993, cited by Rahman) ${ }^{26}$ suggested that placental vascular lesion originate in the fetal circulation rather than in the uteroplacental vasculature. They observed in twin pregnancies complicated by placental insufficiency that there is mircrovascular disease restricted to the placenta of the affected fetus.

There is a commonly accepted concept that human placenta is an aging organ and degenerative changes in vessels resembling adult atherosclerosis are also seen in the placenta ${ }^{6}$. So the patho-physiological process, which presents in normal pregnancies is accentuated or altered in pregnancy-related disorders. This concept still prevails and is considered with due

J Bangladesh Soc Physiol. 2006 Dec;(1):27-34 


\section{Article}

importance. Fernandez et $\mathrm{l}^{12}$ suggested that lipid change during pregnancy is a result of physiological adaptations to the state of pregnancy, which supports the above-mentioned concept.

Atherosclerosis is a systemic disorder causing arterial stenosis or occlusion, although there are some other factors responsible for arterial stenosis or occlusion other than atherosclerosis. Atherosclerosis itself is causes by several factors. As mentioned in introduction, some hypotheses have been put forward for the mechanism atherosclerosis:

i) Injury hypothesis, ii) Smooth muscle cell proliferation and monoclonal hypothesis, iii) Chronic inflammatory response as described in introduction.

However, in a particular case of atherosclerosis, all the above may not be involved simultaneously. Fatty streak is the initial event in the development of atherosclerosis while fibrinoid necrosis with perivascular mononuclear cell infiltration with lipophages comes as a late phenomenon ${ }^{19}$. There is accumulation of lipids, primarily cholesterol in its esterified form, in the intima. Low Density Lipoprotein (LDL) is the source of cholesterol. Why LDL increases in pregnancy causing accumulation in arterial wall can be explained by describing the lipid metabolism in pregnancy and pregnancy-related disorders. Fernandez et $\mathrm{al}^{12}$ stated that apo-A level decreases significantly during delivery compared to be predelivery values. The reliable index of plasma atherogenicity is the apo-B/apo-A ratio. It is significantly greater during delivery than at previous gestational stages. This indicates that lipoprotien profile becomes progressively more atherogenic up to the moment of birth and the changes have hemorheological consequence in the neonate causing an increase in plasma viscosity ${ }^{12}$. Desoye and Shafrir ${ }^{9}$ stated that the elevated lipid concentration promotes the transfer of free fatty acids (FFAs) and triglycerides (TGs) across the placenta by increasing the maternal- fetal concentration gradient and by making other diabetes-related alterations that may promote placenta's fat accumulation. However, for intimal thickening, the elevated lipid alone cannot be responsible. Gradual accumulation of collagen, glycoproteins and proteoglycans in the intima causes intimal thickening in atherosclerosis ${ }^{26}$. As mentioned in introduction smooth muscle cells migrating from the media proliferate in the intima causing intimal thickening. These cells continue to proliferate as the lesion grows, but it is not clear whether smooth muscle is the prerequisite for excessive matrix accumulation.

The present study did not reveal any comprehensive tendency of higher or lower level of atherosclerosis in the Overt Diabetic group. In diabetes, uteroplacental blood flow is reduced by 35 to $45 \%$, 11 . It occurs due to narrowing of the lumen of placental bed arteries ${ }^{9}$, by enlargement of placental villi with resulting reduction in intervillous spaces ${ }^{9}$. In diabetes, there may be increased production of Very Low Density Lipoprotein (VLDL) or a decreased removal of VLDL or LDL from the circulation causing increased concentration of VLDL in the plasma. Thus, the plasma cholesterol level rises and this is responsible for the development of the atherosclerotic vascular lesion 14

Hypertension and placental circulation

Hypertension (usually in preeclampsia) has been shown to be responsible for decreasing uteroplacental blood flow ${ }^{26}$. It is due to swollen endothelial cells causing almost occlusion of large vessels and endothelial degeneration 16 , hyperplastic atherosclerosis, characterized by intimal hyperplasia and medial hypertrophy with narrowing of lumen ${ }^{16}$.

Brosens ${ }^{5}$ stated that in essential hypertension the changes in placental bed arteries are the same as in normal pregnancy. Sheppard \& Bonnar ${ }^{9}$ and Frusca et $\mathrm{al}^{13}$ reported the absence of changes in hypertension whereas Robertson et al 27 


\section{Article}

described that the change was less than adequate in the placental bed arteries in hypertension.

The changes may be the secondary effects of haemodynamic changes that occur in the fetal circulatory system in placental insufficiency. Reduction of uteroplacental blood flow or fetal hypoxia is followed by a rise in fetal blood pressure that might cause changes in the fetal stem arteries as suggested by Fox 26 .

The results of the present study showed a general trend of an increased intimal thickening at all the three branching sites of the chorionic artery of all the three groups and of a reduced luminal diameter at most branching sites in the placentas from the hypertensive diabetic mothers gaining significance for the $2^{\text {nd }}$ site. However, in most cases, both these atherosclerotic variables were significantly more preeminent in the Hypertensive Diabetic group than in the Overt Diabetic group.

Kong ${ }^{19}$ reported acute atherosis in pregnancies complicated by hypertension. Roberts et al 26 suggested that hypertension during pregnancy associated with insulin resistance causes hyperglycemia and is responsible for pathogenesis in the placenta and in the fetus. Salvatore $^{29}$ described red and white infarction in the placenta in hypertensive diabetic mothers. Brosens ${ }^{5}$ suggested that vascular lesions do not occur in every vessel. They are frequently focal or segmental and one, therefore, is not always present in single or random sections.

Reports on human placenta in diabetes and hypertension include a variety of observations, which are often contradictory. Placental weight has been reported to be increased in diabetes. 10,20,21,33,34,35,37 But some other authors have reported that there is no change in placental weight in well control diabetic mothers as compare to control mothers ${ }^{1,7,22}$.Saintonge and Cote (1983, cited by Rahman ${ }^{26}$ )even reported that placental weight decreases in associated with intrauterine growth retardation.
In the present study, there was a tendency of the placenta to be heavier in overt diabetes than the placenta of control group, although the difference did not reach a statistically significant level conform the findings of Clarson ${ }^{8}$. In diabetes, Discroll ${ }^{12}$ and Clarson et $\mathrm{al}^{7}$ reported that an increase in placental weight was found when diabetes was of a more recent origin than in the patient suffering from grave diabetes angiopathy. Laurini et al ${ }^{20}$ suggested that adequate blood glucose control could not prevent placentomegaly. But some reacherchers 9 emphasized that there was a disappearance of pounced weight difference in the recent years due to improvement in the quality glycine control.

The present study also revealed tendencies of the overt diabetes group to be larger on volume and diameter and of having a large number of cotyledons than the control group, though not at a statistically significant level. Anwer ${ }^{2}$ observed significantly large volume of placenta in overt diabetes.

Hypertension is a cardiovascular disease which is supposed to influence growth of human placenta to some extent. It is also a risk factor for complicated pregnancy, especially when superimposed by preeclampsia. In the present study, there was no significance difference between the hypertensive diabetes and control groups in the terms of placental weight, volume, thickness and number of cotyledons (although these features shown a tendency to decrease in hypertensive diabetes). The absence of difference conforms to Jones and Fox ${ }^{16}$. Soma et al ${ }^{31}$ reported that in hypertension, fetoplacental circulation decreases which causes placental infarction resulting in fetal hypoxia.

Regarding the number of cotyledons Craford ${ }^{15}$ suggested that cotyledons increase steadily in length and weight through out pregnancy, and the damaged cotyledon are replaced by newer ones. Ara ${ }^{3}$, Shahana ${ }^{30}$, Sultana ${ }^{32}$ observed that with an increase in size of the placenta, there was

J Bangladesh Soc Physiol. 2006 Dec;(1):27-34 


\section{Article}

an increase in the number of cotyledons. They suggested that with an increase in the diameter of the placenta, there is an increase in the surface area. This has a positive effect on the number of cotyledons. But none of these authors placed any statistical analysis in this regard.

\section{Author Affiliations}

* 1. Dr M Habibur Rahman, Assistant Professor of Anatomy, Mymensingh Medical College, Mymensingh, Bangladesh

2. Professor Mohsin Khalil, Professor and Head of Anatomy, Mymensingh Medical College, Mymensingh, Bangladesh

3. Dr Roxana Ferdousi, Associate Professor of Anatomy, BSMMU, Shahahbag, Dhaka, Bangladesh

4. Dr AKM Moin Uddin, Assistant Professor of Anatomy, Chittagong Medical College, Chittagong, Bangladesh

5. Dr AHMM Maula Chowdhury, Assistant Professor of Anatomy, Khaleda Zia Medical College, Dhaka, Bangladesh

6. Dr Seheli Zannat Sultana, Assistant Professor of Anatomy, Mymensingh Medical College, Mymensingh, Bangladesh

7. Dr Sabina Mannan, Assistant Professor of Anatomy, Mymensingh Medical College, Mymensingh, Bangladesh

* for correspondence

\section{References}

1. Aladjem S, Perrin E, Fenaroff A. Placental score and neonatal outcome. Obstet Gynecol 1970; 39:591-602.

2. Anwar S. Histomorphological changes of human placenta in diabetes mellitus [thesis]. Dhaka; Dhaka University: 1999.

3. Ara G. A study of the effects of age, parity, duration of pregnancy on the morphology and histology of human placentas [thesis]. Dhaka; Dhaka University: 1977.

4. Beccerra JE, Khoury MJ, Cordero JF, Erickson JD. Diabetes mellitus during pregnancy and the risks for specific birth defects: A population based case control study. Pediatrics 1990; 85:1-9.

5. Brosens IA. Morphological changes in the uteroplacental bed in pregnancy hypertension. Obstet Gynecol 1977; 4(3): 573-93.

6. Burtsein R, Soule SD, Blumenthal HT Louis ST. Histogenesis of pathological processes in placentas of metabolic disease in pregnancy. The diabetic state. Am J Obstet Gynecol 1957; 74:96-104.

7. Clarson C, Gerald JM, Paul GRT, Harding, Chance GW, Haust DM. Placental weight in diabetic pregnancy. Placenta 1989; 10:275-81.

8. Crawford JM. Vascular anatomy of the human placenta. Am J Obstet Gynecol 1962; 84:1543-67.

9 Desoye G, Shafrir E. The human placenta in diabetic pregnancy. Diabetes Reviews 1996; 4:70-89.

10. Discroll SG. The pathology of pregnancy complicated by diabetes mellitus. Med Clin North Am 1965; 49:1053-67.

11. Eriksson UJ, Jansson L. Diabetes in pregnancy: decreased placental blood flow and disturbed fetal development in the rat. Pediatric Research 1984; 18:735-8.

12. Fernandez JU, Hoyos AM, Carballo AM, Prieto AP, Ruiz AV, Cosano CR, et al. Lipoproteins in pregnant women before and during delivery: influence on neonatal haemorheology. J Clin Pathol 1996; 49:120-3.

13. Frusca T, Morrasi, Pecorellins, Grigolato P, Gastaid. A histological feature of uteroplacental vessels in normal and hypertensive patient in relation to birth weight. Br J Obstet Gynecol 1989; 96:835-9.

14. Ganong WF. Review of medical physiology: $18^{\text {th }}$ ed. Stamford: Appleton \& Lange. 1997.

15. Gabbe SG, Me an RK, Goebelsmann UT, Lowensohn RI, Nochimson stman JH, Freem D, et al. Management and outcome of pregnancy in diabetes mellitus: Class B to R. Am J Obstet Gynecol 1977; 129:723-32.

16. Jones JCP, Fox H. An ultrastructural and ultrahistochemical study of the human placenta in material essential hypertension. Placentia 1981; 2:193204.

17. Junqueira LC, Carneiro J, Kelly RO. Basic histology. 9th ed. California: Lange Medical Publications. 1998.

18. Karlsson K, Kjellmen I. The outcome of diabetic pregnancies in relation to mother's blood sugar level. Am J Obstet Gynecol 1972; 112: 213-20.

19. Khong TY. Acute atherosis in pregnancies complicated by hypertension, small-for-gestational age infant, diabetes mellitus [abstract]. Pathol Lab Med 1991; $722-5$.

20. Laurini RN, Visser GHA, Banllegooie EV, Schoots CJF. Morphological findings in placenta of insulin

J Bangladesh Soc Physiol. 2006 Dec;(1):27-34 


\section{Article}

dependant diabetic patients treated with continuous subcutaneous insulin infusion (CSII). Placenta 1987; 8:153-65.

21. Mayhew TM, Sorensen FB, Klebe JG, Jackson MR. The effect of mode of delivery and sex of newborn on placental morphology in control and diabetic pregnancies. J Anat 1993b; 183: 545-52.

22. Mayhew TM, Sorensen FB, Klebe JG, Jackson MR. Growth and maturation of villi in placenta from wellcontrolled diabetic women. Placenta 1994a; 15:57-65.

23. Mills JL, Knopp RM, Simpson JL, Peterson LJ, Metzger BE. Holes LM, et al. Lack of relation of increased malformation rates in infants of diabetes mellitus to glycaemic control during organogenesis. N Engl J Med 1988; 318:671-6.

24. North AF, Mazumdar S, Logrillo VM. Birth weight, gestational age and perinatal deaths in 5471 infants of diabetic mothers. Journal of Pediatrics 1977;90:4447.

25. O' Sullivan JB, Gellis SS, Dandrow RV, Tenney BO. The potential diabetic and her treatment in pregnancy. Obstet Gynecol 1966; 27:683-9.

26. Rahman A. Gross morphological and arterial feature of human placenta in gestational diabetes and eclampsia [thesis]. Dhaka: Dhaka University; 2002.

27. Robertson WB, Brosens I, Dixon G. Uteroplacental vascular pathology. Europ J Obstet Gynecol Reprod Biol. 1975;5/1-2: 47-65.
28. Saintonge J, Cote R. Intrauterine growth retardation and diabetic pregnancy: two types of fetal malnutrition. Am J Obstet Gynecol 1983; 146:194-8.

29. Salvatore CA. The placenta in toxemia: a comparative study. Am J Obstet Gynecol 1968; 102:347-3.

30. Shahana N. A study of human full term placenta in relation to fetal weight in Bangladesh [thesis]. Dhaka: University of Dhaka; 1987.

31. Soma H, Yoshida K, Mukaida T, Tabuchi Y. Morphologic changes in the hypertensive placenta. Contrib Gynecol Obstet 1982;9:58-75.

32. Sultana N. Histomorphological study of human placenta in eclampsia [thesis]. Dhaka: University of Dhaka; 1993.

33. Teasdale F. Histomorphometry of the placenta of the diabetic women: class A diabetes mellitus. Placenta $1981 ; 2: 241-52$.

34. Teasdale F. Histomorphometry of the placenta of the diabetic women: class B diabetic mellitus. Placenta 1983; 4:1-12.

35. Teasdale F. Histomorphometry of the human placenta in class C diabetes mellitus. Placenta 1985; 6:69-82

36. Teasdale F, Jacques GJ. Morphometry of the microvillous membrane of the human placenta in maternal diabetes mellitus. Placenta 1986; 7:81-8.

37. Winick M, Noble A. Cellular growth in human placenta. Pediatrics 1967; 1:216-9. 